\title{
Oolong Tea Extract Induces DNA Damage and Cleavage and Inhibits Breast Cancer Cell Growth and Tumorigenesis
}

\author{
HAIHONG SHI ${ }^{1}$, JIN LIU ${ }^{2}$, YIFAN TU ${ }^{2}$, CARL E. FRETER ${ }^{2}$ and CHUNFA HUANG ${ }^{2}$ \\ ${ }^{1}$ Department of Oncology, The Second Affiliated Hospital of Fujian Medical University, Quanzhou, P.R. China; \\ ${ }^{2}$ Division of Hematology/Oncology, Department of Internal Medicine, \\ School of Medicine, Saint Louis University, Saint Louis, MO, U.S.A.
}

\begin{abstract}
Background/Aim: Breast cancer is the most prevalent and devastating malignant disease among women worldwide. Green tea has been extensively studied for its anti-cancer effects, however, existing literature on the correlation of other types of tea with breast cancer is very limited. Materials and Methods: We used six different breast cancer cell lines $\left(E R^{+}, \mathrm{PR}^{+}\right.$or $\mathrm{HER} 2^{+}$and triple-negative $)$, treated under different concentrations of green, oolong, black and dark tea extracts, and determined their biological effects. Results: We determined cell viability, observed the changes of cell morphology, measured DNA damage and cleavage, and analyzed the effect on soft agar colony formation and growth. Conclusion: Oolong tea, same as green tea, can induce DNA damage and cleavage, play an inhibitory role in breast cancer cell growth, proliferation and tumorigenesis, and was a great potential as a chemopreventive agent against breast cancer.
\end{abstract}

Breast cancer is the most prevalent and devastating malignant disease and the leading cause of cancer-related death among women worldwide (1). In 2018, it is estimated that over 268,670 women in the United States will be diagnosed with breast cancer and more than 41,400 will die (2). Breast cancer varies regarding its genomic background, clinical presentation, morphological feature, and response to therapy $(3,4)$. With longer life expectancy and other reasons, breast cancer incidence is increasing in both developed and developing countries $(1,2)$. Fortunately, due to breast cancer screening, early diagnosis, molecular subtype classification and improvements in treatment, its death rate over the last decade

Correspondence to: Chunfa Huang, Ph.D., Division of Hematology/Oncology, Department of Internal Medicine, School of Medicine, Saint Louis University, 3655 Vista Avenue, West Pavilion, Saint Louis, MO, U.S.A. E-mail: chunfa.huang@health.slu.edu

Key Words: Oolong tea, breast cancer, cell viability, DNA damage and cleavage, soft agar colony formation. is declining (3-6). However, breast cancer is still one of the most challenging diseases, which is responsible for a large fraction of cancer-related morbidities and mortalities in women. Undoubtedly, there is greater need for more effective and less toxic therapeutic drugs and chemo-preventive strategies, in particular, for high-risk and receptor-negative breast cancer.

Over the past several decades, extensive research has identified numerous dietary and phytochemical compounds that have anti-cancer activity (7-9). These compounds can be daily used under conventional dosing with very low or no cytotoxicity. Green tea and its main constituent, epigallocatechin-3-gallate (EGCG), exhibit a wide range of promising pharmacological properties including cancer prevention $(10,11)$. Tea, originated in China, has been used for medicinal purposes since ancient days. According to fermentation which causes the oxidation of catechins and alters their components, tea can be broadly classified into six categories: unfermented green tea, mildly-fermented white and yellow teas, semi-fermented oolong tea and intensivelyfermented black and dark teas. About $78 \%$ the of world's tea production is black tea, $20 \%$ green tea and $2 \%$ oolong tea which is majorly produced in Fujian, China $(12,13)$. Tea leaves are rich in catechins (about $25 \%$ of the dry mass of a fresh tea leaf) including catechin, epicatechin, gallocatechin, epigallo-catechin, epicatechin-3-gallate and EGCG (14). EGCG is the most abundant catechin and accounts for more than $40 \%$ of total catechins in green tea leave (14). The lower incidence of breast cancer and the higher level of green tea consumption in the Asian population have made extensively studies on its anti-cancer property $(10,11)$. Over the past decades, green tea extract and EGCG have been shown to inhibit proliferation of breast cancer cells and carcinogenesis (14-17), which indicates their great potential as chemo-preventive agents. However, a small amount of attention has been paid to other types of tea.

Studies in in vitro cell models have demonstrated that either green tea extract or EGCG regulate multiple signaling pathways that control cell growth, proliferation, angiogenesis, 
apoptosis, migration and tumor invasion, and target many proteins such as EGFR, HER-2, VEGF, ErbB2/3, ERK, cyclin D and E, CDK1 and 4, P27, FAK, RTK, PI3-K, Akt, mTOR, STAT, HIF, TNF $\alpha$, NF-kB, PARP-1, Fas, p53, caspases, Bcl-x, Bax, cytochrome $c$, Apaf-1, JNK, c-Jun, FOXO3, Snail, etc. (9). Animal model and epidemiological studies also showed the association of green tea consumption with the reduced risk of breast cancer (17-26). To test the anticancer property of oolong tea extracts, we analyzed the effect of five different tea extracts on DNA damage and cleavage, cell viability and morphology, and soft agar colony formation in six different breast cancer cell lines and found that oolong teas, like green tea, play an inhibitory role in breast cancer cell growth, proliferation and tumorigenesis.

\section{Materials and Methods}

Reagents. Green tea was obtained from the Dongsheng Tea Company (Shangdong, China). Black tea was obtained from Unilever Liptun Tea Company (Shanghai, China). Pu'er tea, a kind of dark tea (post-fermented) was obtained from Fengqiao Tea Company (Yunnan, China). Two oolong teas, Tieguanyin and Dahongpao, were obtained from Richun Tea Company (Fujian, China). All chemicals were purchased from Sigma Chemicals (St. Louis, MO, USA) or Fisher Scientific (Pittsburgh, PA, USA) unless specified otherwise. RPMI 1640 medium and fetal bovine serum (FBS) were purchased from Hyclone (Logan, UT, USA). The monoclonal anti-GAPDH antibody (0411, SC-47724) was obtained from Santa Cruz Biotechnology, Inc. (Dallas, TX, USA). The polyclonal anti-Phospho-Histone H2A.X (Ser139, pH2AX) antibody (20E3, \#9718) was purchased from Cell Signaling Technology (Danvers, MA, USA). Cell Titer $96^{\circledR}$ Non-Radioactive Cell Proliferation Assay kit (MTT) was purchased from Promega (Madison, WI, USA). Halt protease and phosphatase single-use inhibitor cocktail, SuperSignal West Pico chemiluminescent substrate and BCA protein assay reagent were obtained from Thermo Scientific (Rockford, IL, USA).

Preparation of tea extracts. Six grams of dry tea leaves (green, black, dark and two oolong teas) were cut to small pieces and placed in $50 \mathrm{ml}$ tubes. Boiling water was added to each tube according to $4: 1$ ratio ( $4 \mathrm{ml}$ water/1 $\mathrm{g}$ tea) and screwed the caps. After $30 \mathrm{~min}$ immersion, tea extracts were sterilized by filtration using a $0.22-\mu \mathrm{m}$ filter under force pressure. Tea extracts were stored in $-80^{\circ} \mathrm{C}$ refrigerator for further use.

Cell culture, treatment and analysis. MCF-7 cells were originally provided by Dr. Marvin Rich (Michigan Cancer Foundation, Detroit, MI, USA), and T47D, SKBR3, MDA-MB-231, MDA-MB-436 and MDA-MB-468 cells were purchased from the American Type Culture Collection. The Cells were grown in RPMI 1640 medium supplemented with $10 \%$ FBS, $200 \mathrm{U} / \mathrm{ml}$ penicillin and $200 \mu \mathrm{g} / \mathrm{ml}$ streptomycin. For cell viability assay, different breast cancer cells were plated in 96-well plates at a concentration of 10,000 cells per well in $100 \mu \mathrm{l}$ of culture medium with or without different concentrations of tea extracts. After $72 \mathrm{~h}$ treatment, cell viability was determined using Promega's Cell Titer $96{ }^{\circledR}$ Non-Radioactive Cell Proliferation Assay kit (MTT), according to manufacturer's
Table I. Comparison of breast cancer incidence and death rate in China*.

\begin{tabular}{lcrrr}
\hline & $\begin{array}{c}\text { Crude incidence } \\
\left(1 / 10^{5}\right)\end{array}$ & $\%$ & $\begin{array}{r}\text { Death } \\
\left(1 / 10^{5}\right)\end{array}$ & $\%$ \\
\hline Whole nation $^{1}$ & 41.82 & 100.0 & 9.90 & 100.0 \\
Fujian Province $^{2}$ & 27.21 & 65.1 & 6.18 & 62.4 \\
Oolong tea drinking area $^{3}$ & 20.59 & 49.2 & 3.24 & 32.7 \\
\hline
\end{tabular}

*The data from Chinese and Fujian province Cancer Registry Annual Report $(30,31) .{ }^{1}$ Data derived from Chen et al. (30). ${ }^{2,3}$ Data derived from Zheng et al. (31)

instructions and recorded at absorbance $570 \mathrm{~nm}$ using a Biotek Epoch plate Reader (27). For cell morphology, different breast cancer cells were cultured in 6 -well plates and treated with or without $1 \%$ different tea extracts for $24 \mathrm{~h}$, the cultures were observed and photographed by AMG EVOS Core Cell Imaging System.

DNA damage and cleavage assay. For DNA damage and cleavage assay, the cells cultured in 6-well plates with $85 \%$ confluence were treated with $1 \%$ different tea extracts for $24 \mathrm{~h}$, and the floating and attached cells were harvested and washed once with $1 \times$ PBS. The samples were lysed with a buffer contained $5 \mathrm{mM}$ Tris- $\mathrm{HCl}, \mathrm{pH} 8.0$, $20 \mathrm{mM}$ EDTA, and $0.5 \%$ Triton X-100 on ice for $30 \mathrm{~min}$. Cell lysates were centrifuged at $14,500 \mathrm{rpm}$ for $20 \mathrm{~min}$, and cellular proteins in the supernatant were measured using the BCA protein assay reagent, with BSA as a standard. Equal amount of cellular protein was precipitated by acetone, the pellet was re-suspended in $1 \times$ loading buffer, the samples were incubated at $>99^{\circ} \mathrm{C}$ for $10 \mathrm{~min}$. The samples (15 $\mu \mathrm{g} / \mathrm{lane})$ were subjected to SDS-PAGE, and processed for immunoblotting using the antibodies against $\mathrm{pH} 2 \mathrm{AX}$ and GAPDH (28). The supernatant containing $300 \mu \mathrm{g}$ cellular protein was also precipitated by an equal volume of isopropyl alcohol overnight. The samples were centrifuged at $14,500 \mathrm{rpm}$ for $20 \mathrm{~min}$, and the pellets were re-suspended in $30 \mu \mathrm{l}$ Tris-EDTA buffer with proteinase $\mathrm{K}$ and RNase A for $2-3 \mathrm{~h}$ at $45^{\circ} \mathrm{C}$. DNA fragments were separated on a $1.2 \%$ agarose gel, and photographed by the Fisher's Image System.

Soft-gel colony formation assay. For soft agar colony formation assay, equal volumes of pre-warmed RPMI 1640 containing 20\% FBS and melted $1.2 \%$ agarose solution were mixed and added $150 \mu \mathrm{lmixed}$ medium into each 12 well plates. Agarose-containing medium quickly spread to whole well and the plates were placed at $4^{\circ} \mathrm{C}$ for $30 \mathrm{~min}$ to solidify the bottom agar layer. Different breast cancer cells were dissociated into a single-cell suspension by incubated with $0.25 \%$ trypsin-EDTA solution and passed through $40 \mu \mathrm{m}$ nylon cell strainers. Next, $100 \mu \mathrm{l}$ of cell suspension contained 2500 cells in $10 \%$ FBSRPMI 1640 medium was mixed with $200 \mu \mathrm{l}$ of the mixture of $20 \%$ FBS-RPMI 1640 medium and 1.2\% agarose solution. The cell mixtures were placed on the bottom agar layer, and then immediately solidified at $4^{\circ} \mathrm{C}$ for $15 \mathrm{~min}$. After $24 \mathrm{hrs}$, the wells were added $50 \mu \mathrm{l}$ of $10 \%$ FBS-RPMI 1604 medium with or without $1 \%$ different tea extracts according to experimental design and cultured at $37^{\circ} \mathrm{C}$ and $5 \% \mathrm{CO}_{2}$ incubator. To keep cell health growth, every 5 days was added $50 \mu \mathrm{l} 10 \%$ FBS-RPMI 1640 medium with or without $1 \%$ different tea extracts and continued for 4 weeks. The colonies were photographed by the AMG EVOS Core Cell Imaging System and 

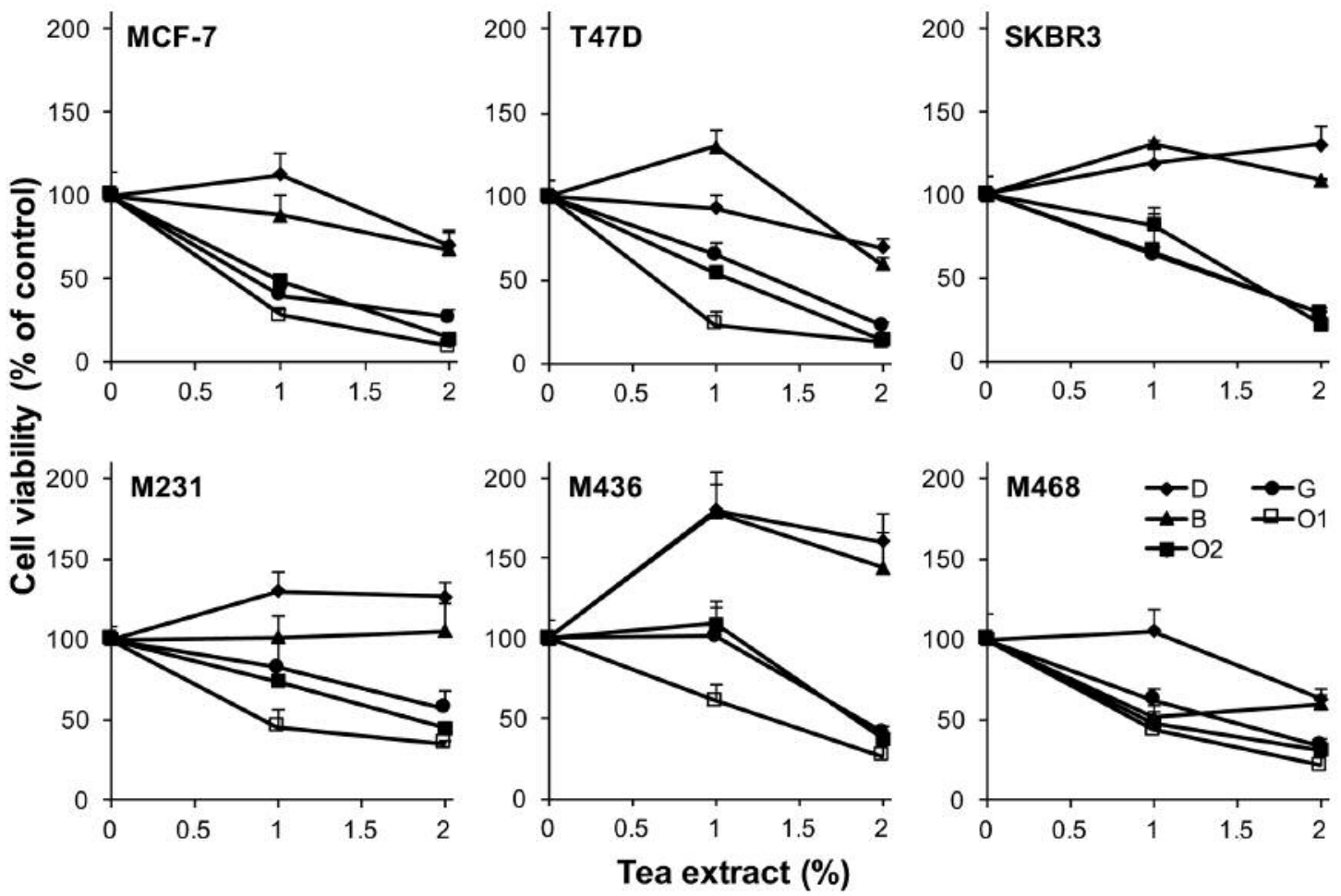

Figure 1. Effect of tea extracts on different breast cancer cell viability. MCF-7, T47D, SKBR3, MDA-MB-231, MDA-MB-436 and MDA-MB-468 cells were treated with or without 1 or $2 \%$ dark $(D)$, green $(G)$, black $(B)$, oolong (Tieguanyin, O1; Dahongpao, O2) tea extracts for 72 h. Cell viability was determined by the MTT assay $(n=12)$. Data represent quadruple samples in three experiments.

quantified by Promega's Cell Titer $96^{\circledR}$ Non-Radioactive Cell Proliferation Assay kit (MTT) (29).

Data analysis. The data were analyzed for significance using oneway repeated measures of ANOVA followed by Tukey's test for comparisons between the experimental groups shown in the figures.

\section{Results}

Oolong tea consumption potentially prevents breast cancer and reduces mortality. Because $78.22 \%$ Chinese oolong tea production in 2015 was from Fujian, China (13), in order to investigate the correlation between oolong tea consumption and breast cancer incidence and death rate, we adapted 2014 data from Chinese and Fujian province cancer registry annual report $(30,31)$. Table I shows that both the incidence and death rate of breast cancer in the Fujian province was much lower than the national average, $35 \%$ decreased in the incidence and $38 \%$ decreased in death rate. The incidence in high oolong tea consumption area decrease another $25 \%$ compared to the average of Fujian and only about $50 \%$ of national level. The death rate reduced $68 \%$ of national average. The lower incidence and death rate of breast cancer and the higher oolong tea consumption indicate that oolong tea has a great potential of anti-cancer property against breast cancer.
Oolong teas inhibit growth and proliferation of different breast cancer cells. To test the anticancer property of oolong tea extracts, we used six different breast cancer cell lines [two $\mathrm{ER}^{+}$and $\mathrm{PR}^{+}$cell lines (MCF-7 and T47D), one HER2 ${ }^{+}$ cell line (SKBR3) and three triple-negative cell lines (MDAMB-231, MDA-MB-436 and MDA-MB-468)], treated under different concentrations of green, black, oolong and dark tea extracts for $72 \mathrm{~h}$, and determined cell viability. As shown in Figure 1, increasing concentration of green and two oolong tea extract resulted in reducing cells viability in all six breast cancer cell lines. However, the effect of cell viability treated with black and dark tea extracts showed no effect or some increase. These results indicate that oolong tea, like green tea, has a similar inhibitory effect in breast cancer cell growth and proliferation.

Oolong tea extracts lead to the changes of different breast cancer cell morphology. Next, we investigate the effect of tea extract on different breast cancer cell morphology. Six breast cancer cells were treated with $1 \%$ different tea extracts for 24 $\mathrm{h}$, and the cells were observed and photographed by AMG EVOS Core Cell Imaging System. Figure 2 illustrated that different breast cancer cells treated with green and oolong tea extracts caused cell shrinkage and plasma membrane damage, 


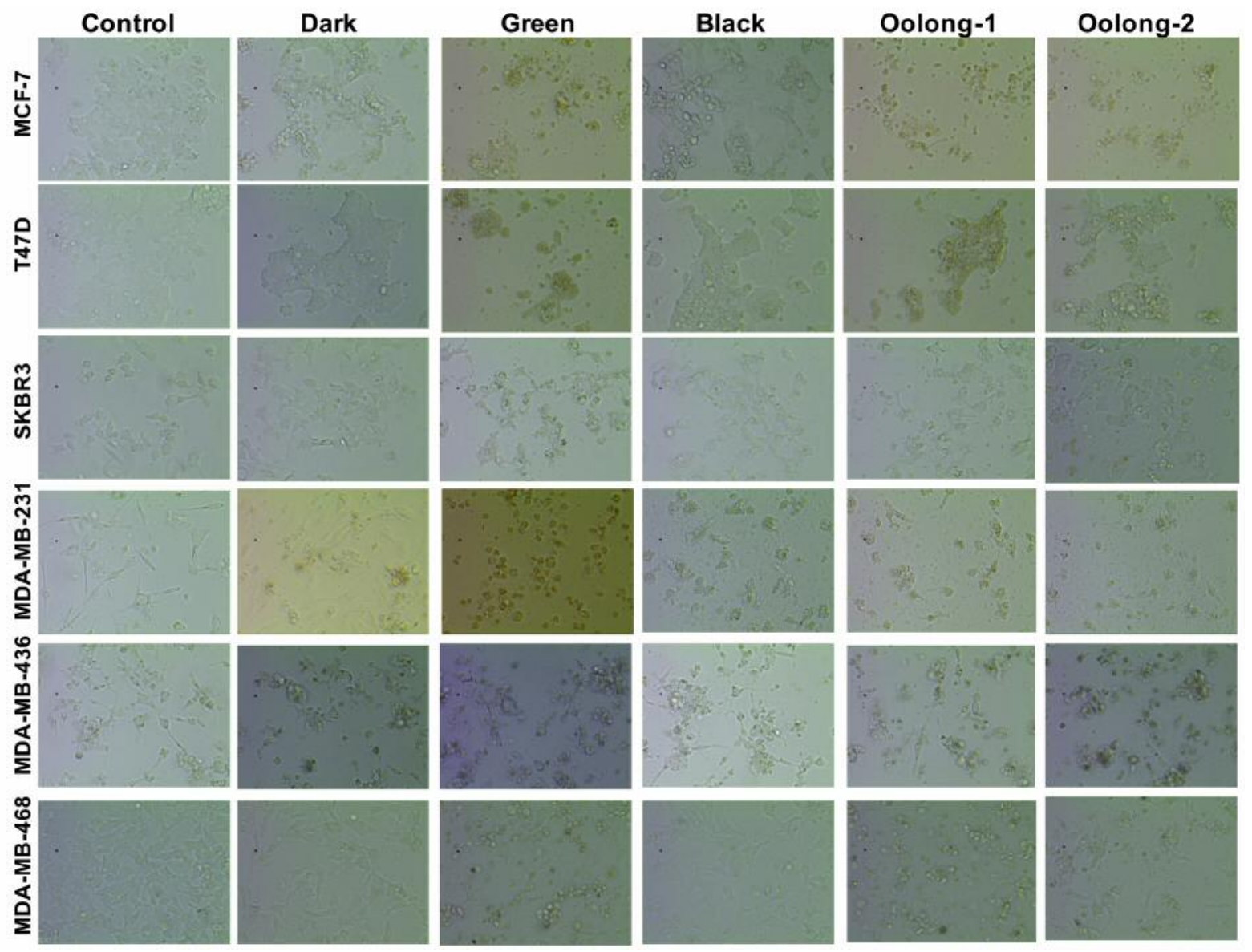

Figure 2. Effect of tea extracts on the morphology of different breast cancer cells. Different breast cancer cells were treated with or without $1 \%$ dark, green, black, oolong-1 (Tieguanyin) and oolong-2 (Dahongpao) tea extracts for 24 h and then the cells were observed and photographed by an AMG EVOS Core Cell Imaging System. Data represent duplicate samples in at least three experiments.

as well as some cell detachment, while black and dark tea extracts had no effect on MCF-7, T47D and SKBR3 cells, and a minus effect on MDA-MB-231, MDA-MB-436 and MDAMB-468 cells. Up to 48 or $72 \mathrm{~h}$ treatment, there were more plasma membrane damage, cell shrinkage and detachment.

Oolong tea extracts cause different breast cancer cell DNA damage and cleavage. DNA damage represents a persistent and ubiquitous threat to genomic stability and the backbone of cancer treatments still rely on drug causing cancer cell DNA damage to accomplish their role (32). Formation of the pH2AX is a wellestablished marker of DNA double strand breaks induced by DNA-damaging compounds (33). We treated six different breast cancer cell lines with different tea extracts, and then cell lysates were processed for immunoblotting to analyze $\mathrm{H} 2 \mathrm{AX}$ phosphorylation. As shown in Figure 3A, all five tea extracts can dramatically induce the formation of $\mathrm{pH} 2 \mathrm{AX}$ in MDA-MB-231, MDA-MB-436 and MDA-MB-468 cells, however, only green and oolong tea extracts stimulate $\mathrm{H} 2 \mathrm{AX}$ phosphorylation in MCF-7, T47D and SKBR3 cells. DNA in all living organisms continually incurs a myriad of types of damage, but cells have devised ingenious mechanisms for tolerating and repairing the damage (34). Next, to test whether DNA damage induced by different tea extracts can be repaired or further lead to cleavage (unreversed changes), we isolated total DNA in the cell lysates and then analyzed the samples. Figure 3B showed that green and oolong tea extracts caused DNA cleavage in six different breast cancer cell lines. Like cell viability, DNA cleavage in black and dark tea extract treated cells were much weaker.

Oolong tea extracts inhibit soft agar colony formation and growth. The colony formation in soft agar is a gold-standard assay for monitoring cellular transformation in vitro and used for a broad range of applications documenting the tumorigenicity of cancer cells (35). We used this technique to test the efficacy of tumor growth inhibition by tea extracts on the tumorigenicity of different breast cancer cells. As shown in Figure 4A-F, the soft agar colonies formed in the wells where different breast cancer cells were planted, although their colony sizes were different. The colonies in soft agar were incubated with or without $1 \%$ 

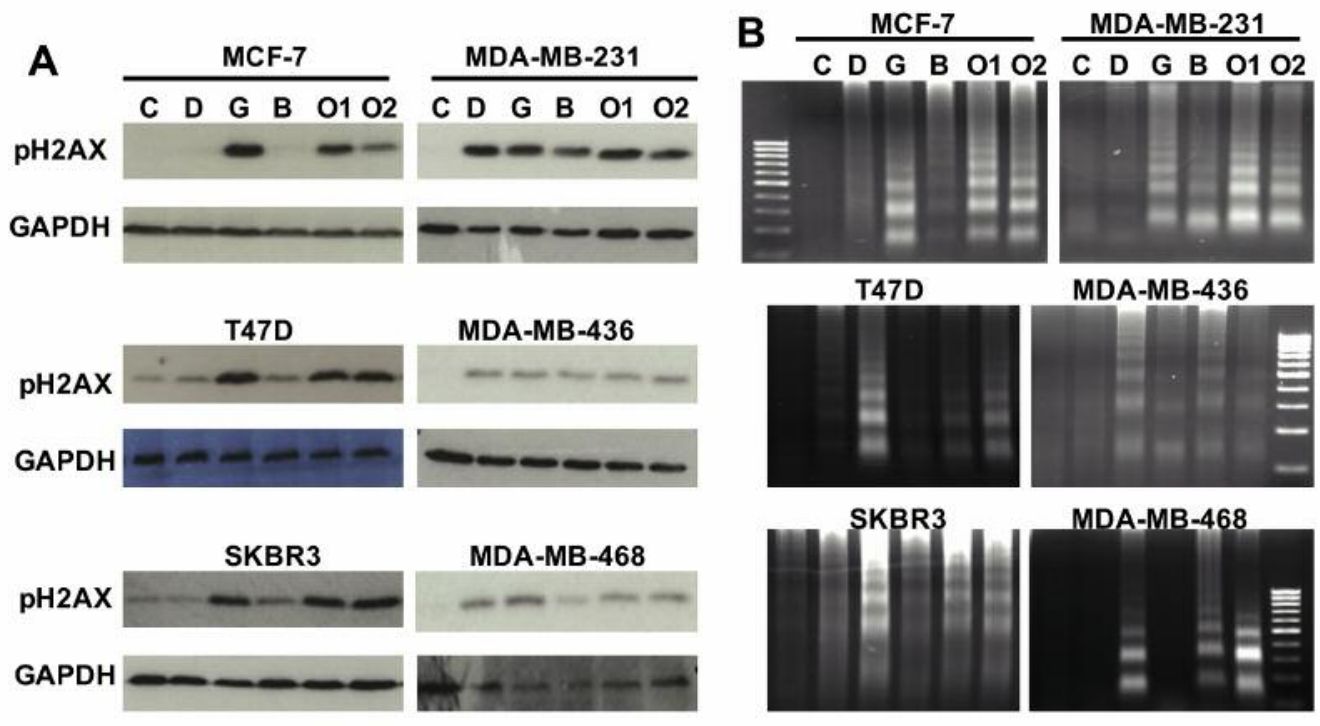

MDA-MB-468

Figure 3. Tea extracts induced H2AX phosphorylation and DNA cleavage in different breast cancer cells. Different breast cancer cells were treated with or without $1 \%$ dark $(D)$, green $(G)$, black $(B)$, oolong (Tieguanyin, O1; Dahongpao, O2) tea extracts for 24 h, harvested, and lysed. The samples were processed for immunoblotting using antibodies against $p H 2 A X$ and GAPDH. The samples were also used for total DNA isolation, and separated on a agarose gel with exACTGene 100 bp DNA ladder. Data represent duplicate samples in at least three experiments.
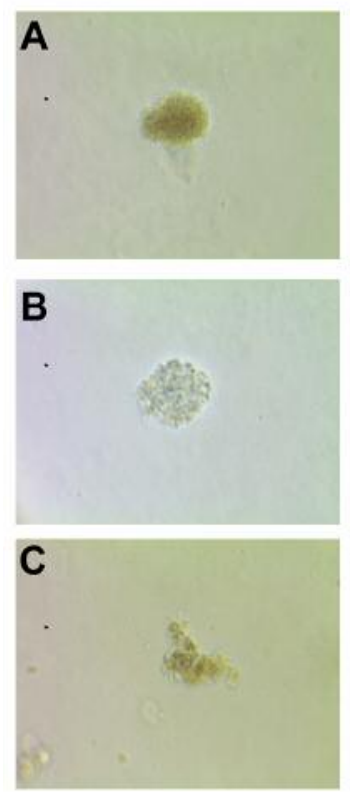
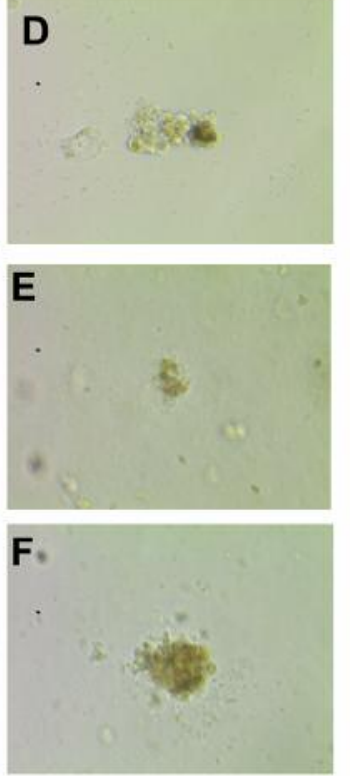

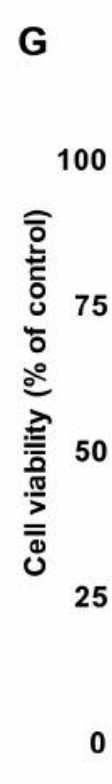

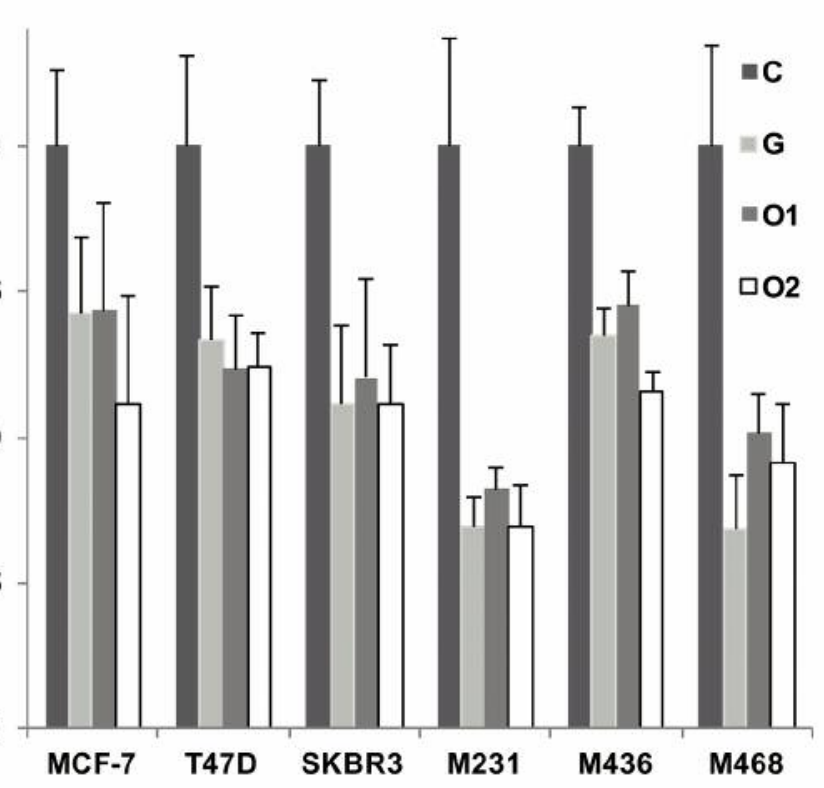

Figure 4. Tea extracts inhibited breast cancer cell soft agar colony formation and growth. Images of MCF-7 (A), T47D (B), SKBR3 (C), MBA-MD$231(D), M D A-M B-436(E)$ and MBA-MD-468 $(F)$ colony in soft agar. Different breast cancer cells were grown in soft agar without tea extracts for 4 weeks, and the colonies were photographed by an AMG EVOS Core Cell Imaging System. G: Quantification of Colony formation and growth. The cells were incubated with or without $1 \%$ green and oolong (Tieguanyin, O1; Dahongpao, O2) tea extracts for 4 weeks, the colonies on the agar were processed for MTT assay. Data represent triplicate samples in two experiments $(n=6)$.

green or oolong tea extracts. After 30 days, the colonies in the cultures were determined by MTT to quantify the effect of tea extracts on colony formation and growth. Figure $4 \mathrm{G}$ shows that both green and oolong tea extracts dramatically reduced the formation and growth of soft agar colonies.

\section{Discussion}

Increasing evidence has supported the role of green tea from a traditional beverage to a source of pharmacologically active molecules in improving health, possibly offering an effect on 
cancer prevention including breast cancer. Analysis by either HPLC (36) or Gas chromatography-mass spectrometry (GCMS) and liquid chromatography-mass spectrometry (LC-MS) (37) shows that green tea has a higher content of catechins than both semi-fermented tea (oolong tea) and fermented teas (black and dark teas). Zhang et al. analyzed 33 different tea samples (12 green teas, 12 oolong teas and 9 black teas) by GC-MS and LC-MS to compare different components and found 90 metabolites with significant difference in three types of tea (37). In HPLC-analyzed samples, the four major catechins are hugely different in green, oolong and black teas. EGCG ranged from 1.4-103.5 mg/g, epigallocatechin from $3.9-45.3 \mathrm{mg} / \mathrm{g}$, epicatechin gallate from $0.2-45.6 \mathrm{mg} / \mathrm{g}$, and epicatechin from $0.6-21.2 \mathrm{mg} / \mathrm{g}$ (36). From tea component analysis $(36,37)$ and breast cancer cell responses to different tea extracts (Figures 1-3), we believe that catechins (epicatechin, epigallo-catechin, epicatechin-3-gallate and EGCG) are not the only components to affect breast cancer behavior, some unidentified and untested components may also play an important role in the regulation of breast cancer cell function.

Either green tea extract or EGCG is involved in the regulation of varying cell signaling pathways in different cancer cells (7-12). We focus on the effect of tea extracts on DNA damage and cleavage. The $\mathrm{pH} 2 \mathrm{AX}$ has been widely recognized as a molecular marker of DNA damage (DNA double-strand break) (38). Black and dark tea extracts did not induce H2AX phosphorylation in MCF-7, T47D and SKBR3 cells (Figure 3A, left panel), but they significantly increased the phosphorylation of $\mathrm{H} 2 \mathrm{AX}$ in three triplenegative cells (Figure 3A, right panel). DNA damage triggers a series of signaling cascades promoting cell survival, including DNA repair, cell-cycle arrest, and autophagy. Whether damaged DNA is repaired or further leads to DNA cleavage? In Figure 3B, green tea and oolong tea extracts not only lead to increasing $\mathrm{pH} 2 \mathrm{AX}$ levels, but also cause DNA cleavage. Although black tea and dark tea extracts can also induce some levels of DNA damage in three triple negative cells, the damage is able to be repaired. These results suggest that triple-negative cells are more sensitive to cause DNA damage, but possess stronger DNA repair system.

Given the inherent difficulties in the mechanisms of different breast cancer progression in vivo and the effect of different tea extracts on breast cancer cell tumorigenesis, animal models will be more difficult to do and to compare. However, cell-based assay such as the soft agar colony formation assay is an effective and useful approach. With the effect of green and oolong tea extracts on breast cancer cell morphology and viability and DNA damage and cleavage, we test the effect of green and oolong tea extracts on soft agar colony formation of different breast cancer cells. The results clearly support that oolong tea, like green tea, inhibited soft agar colony formation and growth.
Epidemiological data from different cohort studies support an inverse association between green tea intake and breast cancer risk. Two Japanese research groups reported that increased consumption of green tea among 472 surgical breast cancer patients (24) and 1,160 new surgical cases of female invasive breast cancers (20) with different stages was significantly associated with improved prognosis and inhibited cell proliferation in stage I and II breast cancer. In a population-based prospective cohort study with 518 women with confirmed triple-negative breast cancer, tea intake was associated with improved survival among women with triplenegative breast cancer (21). A study by interviewing Asian American (501 breast cancer patients and 594 control subjects) showed that green tea drinkers had a significantly reduced risk of breast cancer, in contrast, the risk of breast cancer was not related to black tea consumption (25). In the European Prospective Investigation into Cancer and Nutrition (EPIC) Study, the researchers analyzed 1,064 pre-menopausal and 9,134 postmenopausal breast cancer cases with an average follow-up of 11 years, and found that tea intake was neither associated with pre- nor post-menopausal breast cancer (26). This controversial conclusion may due to most European traditionally dominated consume black tea. There is no such study on oolong tea, but the lower incidence and mortality and the higher oolong tea consumption indicate that oolong tea has a great potential of anti-cancer activity against breast cancer.

\section{Acknowledgements}

Dr. Haihong Shi was supported by China Scholarship Council (201708350090).

\section{Conflicts of Interest}

The Authors declare no potential conflicts of interest.

\section{References}

1 Islami F, Torre LA, Drope JM, Ward EM and Jemal A: Global Cancer in Women: Cancer Control Priorities. Cancer Epidemiol Biomarkers Prev 26: 458-470, 2017.

2 Siegel RL, Miller KD and Jemal A: Cancer statistics, 2018. CA Cancer J Clin 68: 7-30, 2018.

3 Harbeck N and Gnant M: Breast cancer. Lancet 389: 1134-1150, 2017.

4 Perou CM and Børresen-Dale AL: Systems biology and genomics of breast cancer. Cold Spring Harb Perspect Biol 3: pii: a003293, 2011.

5 Zanardi E, Bregni G, de Braud F and Di Cosimo S: Better Together: Targeted Combination Therapies in Breast Cancer. Semin Oncol 42: 887-895, 2015.

6 Lin SX, Chen J, Mazumdar M, Poirier D, Wang C, Azzi A and Zhou M: Molecular therapy of breast cancer: progress and future directions. Nat Rev Endocrinol 6: 485-493, 2010.

7 Nabavi SM, Habtemariam S, Daglia M and Nabavi SF: Apigenin and Breast Cancers: From Chemistry to Medicine. Anticancer Agents Med Chem 15: 728-735, 2015. 
8 Abdull Razis AF and Noor NM: Cruciferous vegetables: dietary phytochemicals for cancer prevention. Asian Pac J Cancer Prev 14: 1565-1570, 2013.

9 Sinha D, Biswas J, Nabavi SM and Bishayee A: Tea phytochemicals for breast cancer prevention and intervention: From bench to bedside and beyond. Semin Cancer Biol 46: 33-54, 2017.

$10 \mathrm{Li}$ MJ, Yin YC, Wang J and Jiang YF: Green tea compounds in breast cancer prevention and treatment. World J Clin Oncol 5: 520-528, 2014.

$11 \mathrm{Wu}$ AH and Butler LM: Green tea and breast cancer. Mol Nutr Food Res 55: 921-930, 2011.

12 Sang S, Lambert JD, Ho CT and Yang CS: The chemistry and biotransformation of tea constituents. Pharmacol Res 64: 87-99, 2011.

13 China Tea Marketing Association: 2015 analytic report of Chinese tea production and consumption and. Tea world 4: 2130, 2016 (In Chinese).

14 Li P, Dai W, Lu M, Xie D, Tan J, Yang C, Zhu Y, Lu H, Peng Q, Zhang Y, Guo L, Ni D, Lin Z: Metabolomic analysis reveals the composition differences in 13 Chinese tea cultivars of different manufacturing suitabilities. J Sci Food Agric 98: 1153-1161, 2018

15 Dong JJ, Ye JH, Lu JL, Zheng XQ and Liang YR: Isolation of antioxidant catechins from green tea and its decaffeination. Food Bioprod Process 89: 62-66, 2011.

16 Pianetti S, Guo S, Kavanagh KT and Sonenshein GE: Green tea polyphenol epigallocatechin-3 gallate inhibits Her-2/neu signaling, proliferation, and transformed phenotype of breast cancer cells. Cancer Res 62: 652-655, 2002.

17 Yang CS, Wang X, Lu G and Picinich SC: Cancer prevention by tea: animal studies, molecular mechanisms and human relevance. Nat Rev Cancer 9: 429-439, 2009.

18 Baliga MS, Meleth S and Katiyar SK: Growth inhibitory and antimetastatic effect of green tea polyphenols on metastasisspecific mouse mammary carcinoma $4 \mathrm{~T} 1$ cells in vitro and in vivo systems. Clin Cancer Res 11: 1918-1927, 2015.

19 Zhang G, Wang Y, Zhang Y, Wan X, Li J, Liu K, Wang F, Liu K, Liu Q, Yang C, Yu P, Huang Y, Wang S, Jiang P, Qu Z, Luan J, Duan H, Zhang L, Hou A, Jin S, Hsieh TC, Wu E: Anti-cancer activities of tea epigallocatechin-3-gallate in breast cancer patients under radiotherapy. Curr Mol Med 12: 163-176, 2012.

20 Yu SS, Spicer DV, Hawes D, Tseng CC, Yang CS, Pike MC and Wu AH: Biological effects of green tea capsule supplementation in pre-surgery postmenopausal breast cancer patients. Front Oncol 3: 298, 2013.

21 Bao PP, Zhao GM, Shu XO, Peng P, Cai H, Lu W and Zheng Y: Modifiable Lifestyle Factors and Triple-negative Breast Cancer Survival: A Population-based Prospective Study. Epidemiology 26: 909-916, 2015.

22 Inoue M, Tajima K, Mizutani M, Iwata H, Iwase T, Miura S, Hirose $\mathrm{K}$, Hamajima $\mathrm{N}$ and Tominaga $\mathrm{S}$ : Regular consumption of green tea and the risk of breast cancer recurrence: follow-up study from the Hospital-based Epidemiologic Research Program at Aichi Cancer Center (HERPACC), Japan. Cancer Lett 167: 175-182, 2001.

23 Kavanagh KT, Hafer LJ, Kim DW, Mann KK, Sherr DH, Rogers $\mathrm{AE}$ and Sonenshein GE: Green tea extracts decrease carcinogeninduced mammary tumor burden in rats and rate of breast cancer cell proliferation in culture. J Cell Biochem 82: 387-398, 2001.

24 Nakachi K, Suemasu K, Suga K, Takeo T, Imai K, Higashi Y: Influence of drinking green tea on breast cancer malignancy among Japanese patients. Jpn J Cancer Res 89: 254-261, 1998.
$25 \mathrm{Wu}$ AH, Yu MC, Tseng CC, Hankin J and Pike MC: Green tea and risk of breast cancer in Asian Americans. Int J Cancer 106: 574-579, 2003.

26 Bhoo-Pathy N, Peeters PH, Uiterwaal CS, Bueno-de-Mesquita HB, Bulgiba AM, Bech BH, Overvad K, Tjønneland A, Olsen A, Clavel-Chapelon F, Fagherazzi G, Perquier F, Teucher B, Kaaks R, Schütze $M$, Boeing $H$, Lagiou $P$, Orfanos $P$, Trichopoulou A, Agnoli C, Mattiello A, Palli D, Tumino R, Sacerdote C, van Duijnhoven FJ, Braaten T, Lund E, Skeie G, Redondo ML, Buckland G, Pérez MJ, Chirlaque MD, Ardanaz E, Amiano P, Wirfält E, Wallström P, Johansson I, Nilsson LM, Khaw KT, Wareham N, Allen NE, Key TJ, Rinaldi S, Romieu I, Gallo V, Riboli E and van Gils $\mathrm{CH}$ : Coffee and tea consumption and risk of pre- and postmenopausal breast cancer in the European Prospective Investigation into Cancer and Nutrition (EPIC) cohort study. Breast Cancer Res 17: 15, 2015.

27 Benakanakere I, Johnson T, Sleightholm R, Villeda V, Arya M, Bobba R, Freter C and Huang C: Targeting cholesterol synthesis increases chemoimmuno-sensitivity in chronic lymphocytic leukemia cells. Exp Hematol Oncol 3: 24, 2014.

28 Huang C, Miller R.T and Freter CE: Signaling regulation and role of filamin A cleavage in $\mathrm{Ca}^{2+}$-stimulated migration of androgen receptor-deficient prostate cancer cells. Oncotarget 8 : 3840-3853, 2017.

29 Rotem A, Janzer A, Izar B, Ji Z, Doench JG, Garraway LA and Struhl K: Alternative to the soft-agar assay that permits highthroughput drug and genetic screens for cellular transformation. Proc Natl Acad Sci USA 112: 5708-5713, 2015.

30 Chen W, Sun K, Zheng R, Zeng H, Zhang S, Xia C, Yang Z, Li $\mathrm{H}$, Zou $\mathrm{X}$ and He J: Cancer incidence and mortality in China, 2014. Chin J Cancer Res 30: 1-12, 2018.

31 Zheng XW (ed): 2017 Fujian cancer registry annual report. The Straits Publishing \& Distributing Group, Fujian, 2018 (In Chinese).

32 Basu B, Yap TA, Molife LR and de Bono JS: Targeting the DNA damage response in oncology: past, present and future perspectives. Curr Opin Oncol 24: 316-324, 2012.

33 Mah LJ, El-Osta A and Karagiannis TC: gammaH2AX: a sensitive molecular marker of DNA damage and repair. Leukemia 24: 679-686, 2010.

34 Friedberg EC: DNA damage and repair. Nature 421: 436-440, 2003.

35 Pampaloni F, Reynaud EG and Stelzer EH: The third dimension bridges the gap between cell culture and live tissue. Nat Rev Mol Cell Biol 8: 839-845, 2007.

36 Cabrera C, Giménez R and López MC: Determination of tea components with antioxidant activity. J Agric Food Chem 51: 4427-4435, 2003.

37 Zhang L, Zeng Z, Ye G, Zhao C, Lu X and Xu G: Non-targeted metabolomics study for the analysis of chemical compositions in three types of tea by using gas chromatograph-mass spectrometry and liquid chromatography-mass spectrometry. Se $\mathrm{Pu}$ 32: 804-816, 2014.

38 Kinner A, Wu W, Staudt C and Iliakis G: $\gamma-\mathrm{H} 2 \mathrm{AX}$ in recognition and signaling of DNA double-strand breaks in the context of chromatin. Nucleic Acids Res 36: 5678-5694, 2008.

Received September 10, 2018

Revised October 16, 2018

Accepted October 19, 2018 